\title{
Appearance of annulate lamellae in mouse Leydig cell tumors accompanied by acquisition of estrogen dependency
}

\author{
Hiroshi Mori', Bunzo Sato 2 , Yasuko Nishizawa 2 , Yoshiaki Maeda ${ }^{2}$, \\ Hiroshi Ueno', Fumio Chatani ${ }^{1}$ and Keishi Matsumoto \\ ${ }^{1}$ Second Department of Pathology, and ${ }^{2}$ Third Department of Internal Medicine, Osaka University \\ School of Medicine, Osaka 530, Japan
}

\begin{abstract}
Growth of original Leydig cell tumors (LCTs) induced by estrogen and of transplantable Leydig cell tumors is generally dependent on estrogen. A subline T124958, which grew even in the absence of estrogen, was established during the successive transplantation. Further transplantation of T124958 under the stimulation of diethylstilbestrol (DES) yielded an estrogen-dependent subline T124958-R. Electron microscopy revealed the presence of annulate lamellae in T124958-R, but not in T124958. The annulate lamellae are unique membranous structures which are assumed to be involved in the transport of genetic information from the nucleus to the cytoplasm and in the active protein synthesis. Tumor cells with annulate lamellae were more frequent in T124958-R tumors treated with estrogen than in estrogen-untreated tumors, in parallel with the growth rate of these tumors. Appearance of annulate lamellae in T124958-R tumors may relate to a marked increase in cytosol estrogen receptors which are almost absent in the T124958 tumors. This is the first report which demonstrates the annulate lamellae in either normal or neoplastic Leydig cells.
\end{abstract}

Hormone-dependent tumors such as prostatic (2) and breast cancers (1) possess hormone receptors, and are sensitive for endocrine therapy. Recurrent tumors, however, frequently lose the hormone dependency (5). We have reported that in Shionogi carcinoma 115, an androgen-dependent breast cancer in mice, hormone dependency can be altered concomitantly with a histological change during the successive transplantation (6). In general, however, morphological alterations which may be associated with hormone-dependency are not frequent.

Estrogen-induced Leydig cell tumor (LCT) in $\mathrm{BALB} / \mathrm{c}$ mice is also a hormone-dependent tumor $(3,13)$. Both original LCTs induced by implantation of $10 \mathrm{mg}$ of diethylstilbestrol (DES) pellet (10\% in cholesterol) and transplantable LCTs in earlier generations grew in the presence of DES and regressed in the absence of DES. During the successive transplantation, however, we obtained a subline (T124958) which grew even in the absence of DES and showed slightly accelerated growth in the presence of DES. Further transplantations under the stimulation with DES yielded an estrogen-dependent subline T124958-R. The growth of T124958-R tumors was remarkably accelerated in the presence of DES and suppressed in the absence of DES, in contrast to T124958 tumors. Establishment of these cell lines and their characteristics were reported elsewhere $(12,13$; and unpublished data).

In these LCT sublines, we observed a histological change, i.e. the appearance of annulate lamellae. The annulate lamellae are unique and definite structures. They have been found most frequently in germ cells (oocytes and spermatocytes), and less frequently in embryonic or fetal cells, and in rapidly growing neoplastic somatic cells $(4,16)$. Several kinds of endocrine cells, 
particularly the neoplastic cells have been reported to possess annulate lamellae (10). However, the occurrence of the annulate lamellae in the Leydig cells, either normal or neoplastic, has not yet been reported. To the best of our knowledge, the present study is the first to report the annulate lamellae in the Leydig cells.

Tumors examined in the present study include 1) T124958 of the 29th, 30th and 31st generations in the absence of DES, 2) T124958-R of the 11 th generation in the presence of DES, and 3) T124958-R of the 10th generation in the absence of DES. Tumor tissues were fixed in 3\% glutaraldehyde buffered with $0.1 \mathrm{M}$ s-collidine, $\mathrm{pH} 7.4$ and postfixed in $1 \%$ osmium tetroxide. Thin sections cut from epon blocks were contrasted with uranyl acetate and lead citrate and viewed in a Hitachi 12 electron microscope at $100 \mathrm{kV}$.

Leydig cell tumors of subline T124958 and T124958-R showed almost similar histological appearance. The tumor cells aggregated compactly, showing an epithelioid appearance. They were fairly uniform in size. The nucleus was ovoid or slightly elongated in shape, and the nucleoli were prominent. In the absence of DES, however, T124958-R cells showed irregularity in their size. The nucleus was larger in size and irregular in shape. Multinuclear giant cells were occasionally seen. Mitotic figures were less frequently seen in the absence of DES than in its presence.

Fine structural characteristics of LCTs of both T124958 and T124958-R sublines were similar to those reported previously, either in primary tumors (7) or in transplantable cell lines (14). These include poorly developed smooth endoplasmic reticulum (SER), moderately developed rough endoplasmic reticulum (RER), a number of mitochondria with numerous tubular cristae and virus particles (Fig.1). In normal Leydig

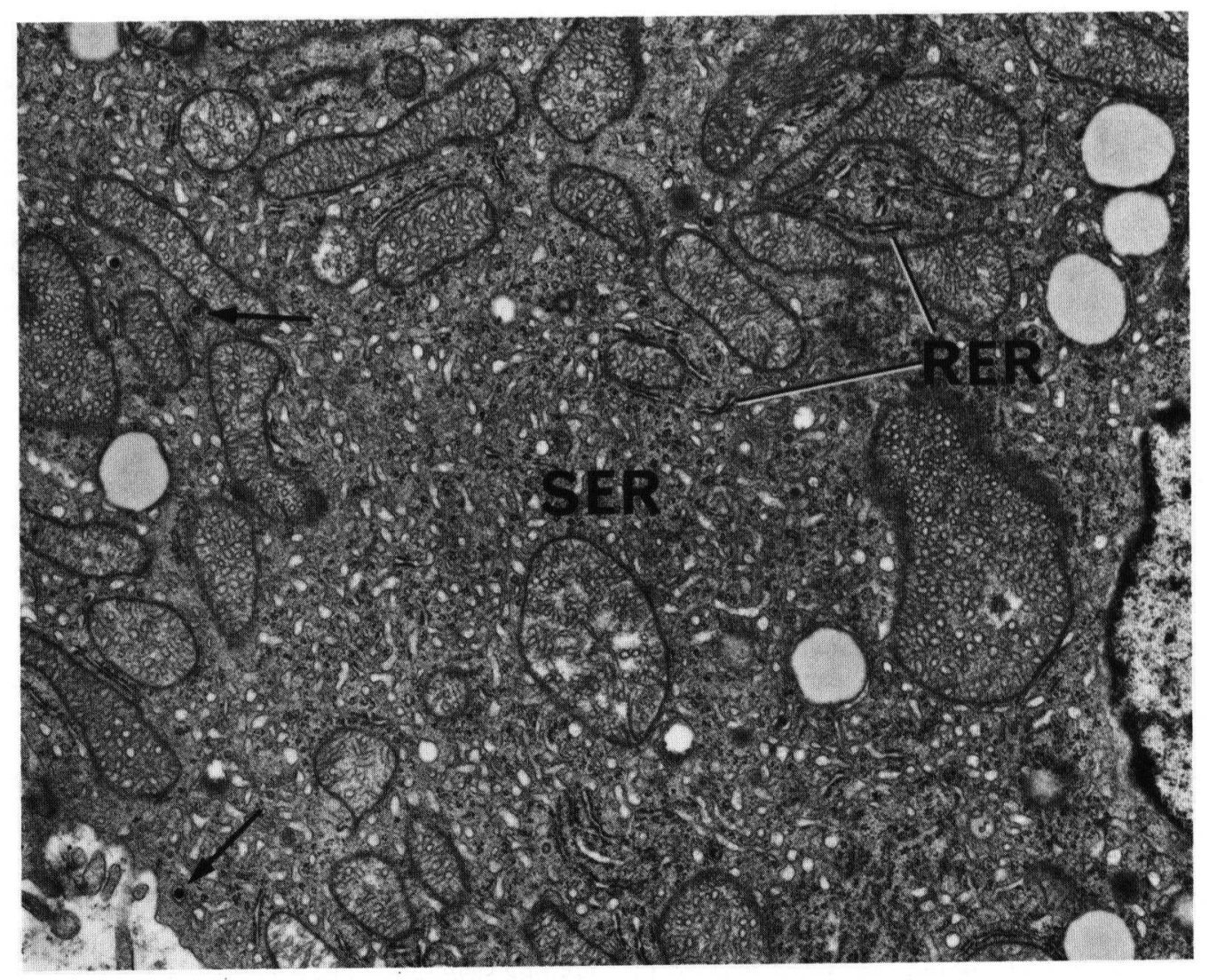

Fig. 1 Cytoplasm of T124958 Leydig cell tumor (LCT) contains a number of mitochondria with numerous tubular cristae and virus particles of intracisternal A type (arrows). The rough endoplasmic reticulum (RER) is moderate, but smooth endoplasmic reticulum (SER) is poor, compared to the normal Leydig cells. No annulate lamellae are seen. $\times 12,000$ 
cells, abundance of SER roughly parallels the androgen production with some variations in its efficiency between species (9). In contrast to an extensive development of SER and more active production of androgen in normal mouse Leydig cells (11), development of SER is poor and androgen production is less active in the LCTs (8). Inversely, RER and free ribosomes were well developed in neoplastic Leydig cells than in normal Leydig cells. This seems to reflect the proliferative activity of LCTs. Numerous virus particles, predominantly of intracisternal A type, were found in all tumors examined in the present study. The presence of virus particles is not a prerequisite for tumorigenesis of LCTs (7), and repetitive transplantation might cause estrogendependent derepression of a viral genome incorporated into the Leydig cell genome (15). No definite difference in number of virus particles was seen between the sublines examined in the present study, suggesting that virus genome is not responsible for the changes in estrogen-sensitivity in the tumor growth.

A definite difference between T124958-R and
T124958 was the presence of annulate lamellae in the former (Fig. 2). The annulate lamellae consisted of one to six parallel stacks of smoothwalled cisternae with annuli. In cross sections, smooth-walled cisternae appeared to be interrupted by a centrally placed diaphragm 70-85 $\mathrm{nm}$ in length and $8-10 \mathrm{~nm}$ in width, with an interval of 140-160 nm. Fine filamentous materials with moderate electron density accumulated between each lamella. In sections parallel to the cisternae, annuli with a diameter of $100-$ $110 \mathrm{~nm}$ were arranged at regular intervals (Fig. $3)$. At one or both ends, lamellae were continuous with RER or SER. Interestingly, virus particles were present in the lumen of, or formed on the membrane of, those dilated endoplasmic reticulum (ER), which were partly studded with ribosomes and continuous with annulate lamellae (Fig. 4). Tumor cells with annulate lamellae were observed more frequently in the presence than in the absence of DES.

Although their functional role has not been established, the annulate lamellae have been assumed to be involved in the transport of genet-

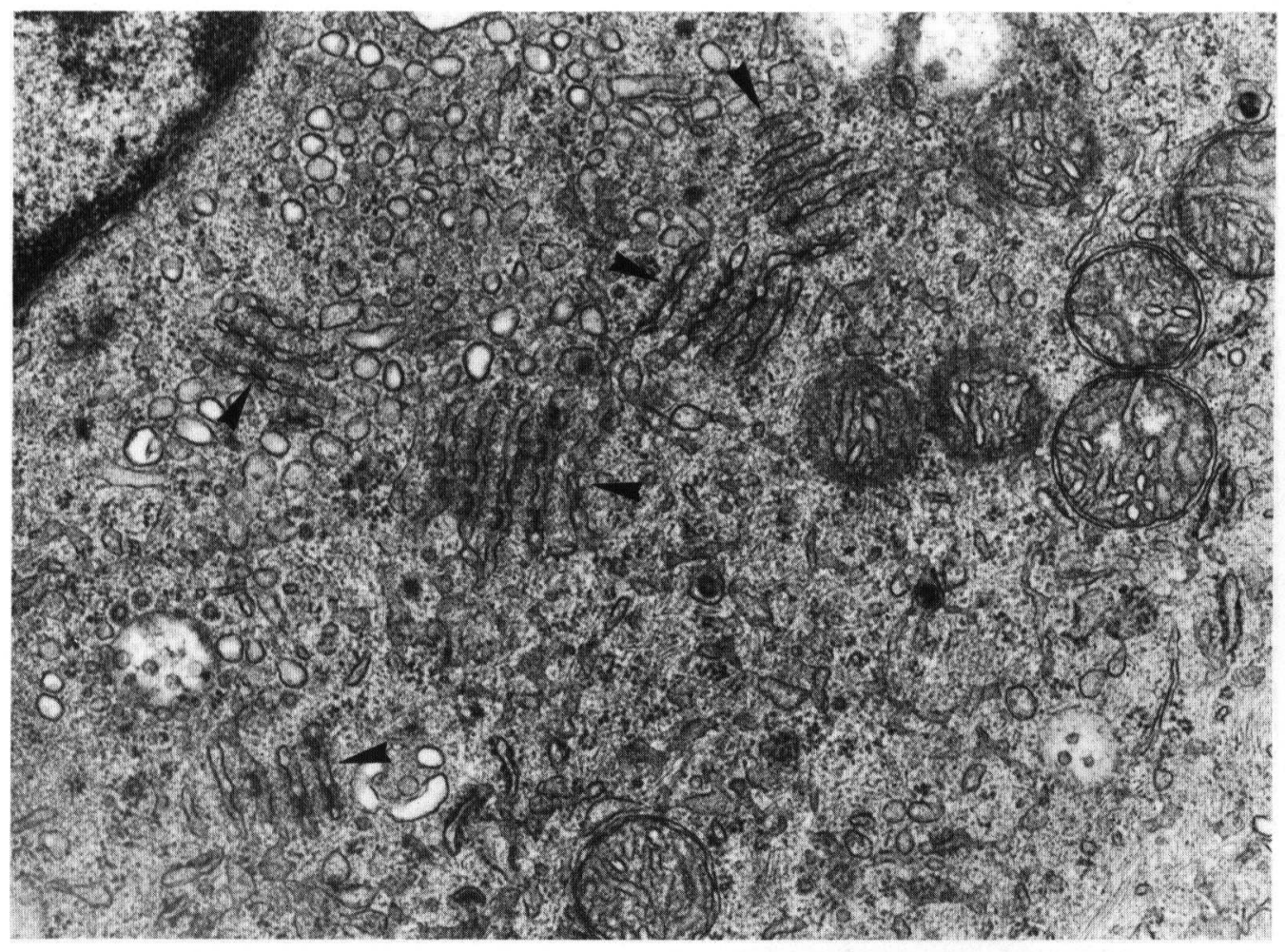

Fig. 2 Several aggregates of the annulate lamellae (arrowheads) are seen in the cytoplasm of estrogen-sensitive T124958-R tumors. $\times 23,000$ 


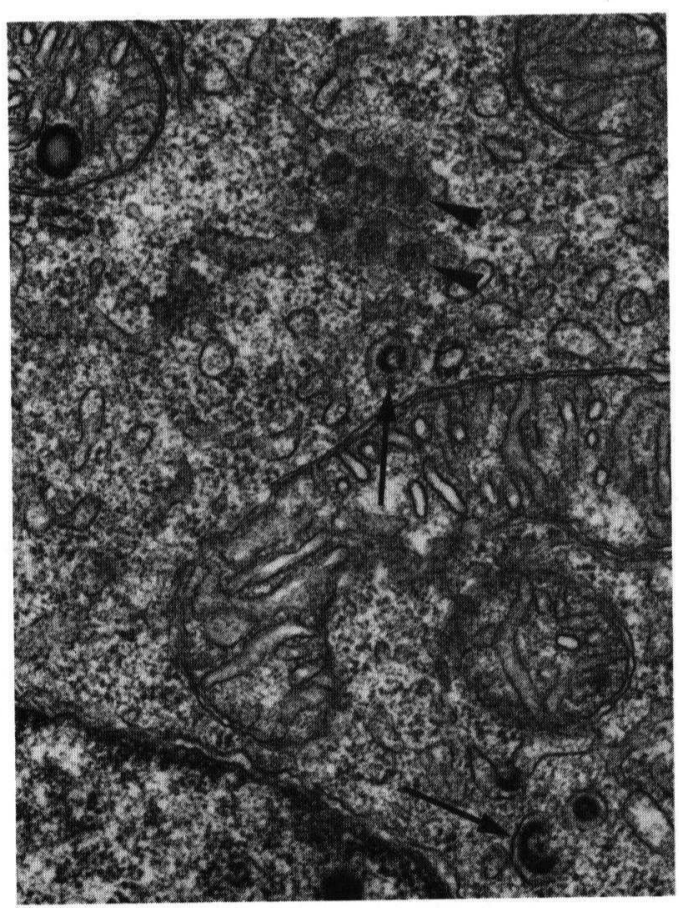

Fig. 3 In a section parallel to the cisternae, annuli (arrowheads) are arranged at regular intervals. Arrows indicate virus particles. $\times 27,000$

ic information from the nucleus to the cytoplasm and in active protein synthesis $(4,16)$. The assumption is based on the findings that the annulate lamellae are commonly seen in the germ cells and rapidly growing somatic cells, though they may occur in a wide spectrum of cell types $(4,16)$. In the present study, the LCT of subline T124958-R in the presence of estrogen grew more rapidly and had more annulate lamellae than in the absence of estrogen, consistently with the above hypothesis. However, we have no explanation for the appearance of the annulate lamellae in the subline T124958-R associated with acquisition of estrogen-dependency. It is possible that LCT cells possessing annulate lamellae exist in the subline T124958, and treatment with estrogen for selection of estrogen-sensitive tumors allows the LCT cells with annulate lamellae to predominate over the LCT cells without annulate lamellae. Specific estrogen binding sites were present in the nucleus but almost absent in the cytosol of T124958 tumors. With acquisition of estrogen-dependency in T124958-R, estrogen binding sites increased markedly in the cytosol and decreased in the

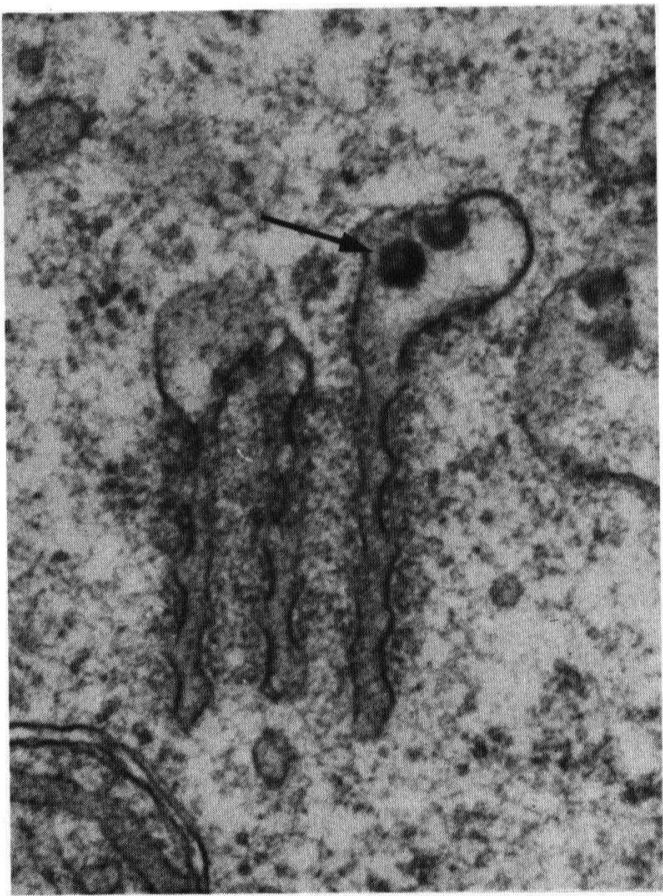

Fig. 4 Virus particles (arrows) are seen in a dilated end of lamella. $\times 53,000$

nucleus, suggesting that annulate lamellae in the T124958-R tumors are involved in the transport of estrogenic signals from the nucleus. Biochemical and molecular analyses of dynamics of estrogen receptors will help to clarify this implication.

Received for publication 11 June 1984

\section{REFERENCES}

1. DAO T. L. (1972) Ablation therapy for hormonedependent tumors. Annu. Rev. Med. 23, 1-18

2. Ekman P., Snochowski M., Zetterberg A., HögBerg B. and Gustafsson J.-Å. (1979) Steroid receptor content in human prostatic carcinoma and response to endocrine therapy. Cancer 44, 1173-1181

3. GARDNER W. U. (1945) Some influences of hormones on the growth and persistence of transplanted testicular tumors. Cancer Res. 5, 497-505

4. Kessel R. G. (1968) Annulate lamellae. J. Ultrastruct. Res. Suppl. 10, 5-82

5. Kiang D. T., Frenning D. H., Goldman A. I., AsCENSAO V. F. and KeNNEDY B. J. (1978) Estrogen receptors and responses to chemotherapy and hormonal therapy in advanced breast cancer. $N$. Engl. 
J. Med. 299, 1330-1334

6. Kitamura Y., Okamoto S., Hayata I., Uchida N., Yamaguchi K. and Matsumoto K. (1979) Development of androgen-independent spindle cell tumors from androgen-dependent medullary Shionogi carcinoma 115 in androgen-depleted nude mice. Cancer Res. 39, 4713-4719

7. Kurland G., Christensen A. K. and Huseby R. A. (1975) Changes in fine structure accompanying etrogen-induced tumorigenesis of Leydig cells in the mouse testis. Cancer Res. 35, 1671-1686

8. Maeda Y., Sato B., Noma K., Kishimoto S., Koizumi K., Aono T. and Matsumoto K. (1983) Characterization of a unique nuclear estrogenbinding component in an estrogen-responsive mouse Leydig cell tumor. Cancer Res. 43, 40914097

9. Mori H. (1984) Ultrastructure and stereological analysis of Leydig cells. In Ultrastructure of Endocrine Cells and Tissues (ed. MotтA P. M.) Martinus Nijhoff Publishers, Boston, pp. 225-237

10. Mori H., Mori S., Saitoh Y., Koizumi K. and AONo T. (1983) Annulate lamellae in prolactinsecreting pituitary adenomas. Acta Neuropathol.
61, 10-14

11. Mori H., Shimizu D., Fukunishi R. and ChristenSEN A. K. (1982) Morphometric analysis of testicular Leydig cells in normal adult mice. Anat. Rec. 204, 333-339

12. Sato B., Huseby R. A. and Samuels L. T. (1978) The possible roles of membrane organization in the activity of androgen biosynthetic enzymes associated with normal or tumorous mouse Leydig cell microsomes. Endocrinology 103, 805-816

13. Sato B., Yamamura Y., Huseby R. A. and Matsuмото K. (1980) Estrogen receptor systems in normal and neoplastic Leydig cells of the mouse. Adv. Sex Horm. Res. 4, 241-271

14. Stephens R. J., Pourreau-Schneider N. and GARDNER W. U. (1968) Cytological morphology of a virus-containing mouse testicular interstitial cell tumor. J. Ultrastruct. Res. 22, 494-507

15. Todaro G. J. and Huebner R. J. (1972) The viral oncogene hypothesis: New evidence. Proc. Natl. Acad. Sci. USA 69, 1009-1015

16. WischnitZer S. (1970) The annulate lamellae. Int. Rev. Cytol. 27, 65-100 